Vol. 8, Issue 10, October 2021

DOI: $10.17148 /$ IARJSET.2021.81028

\title{
The Green Costume and the Sets of Hollywood Movies- A Road Towards Sustainability
}

\author{
Ms.Priyanka.P1, Mr.Melwin Samuel.R ${ }^{2}$, Ms.N.P.Swetha Menon ${ }^{3}$ \\ ${ }^{1}$ Assistant Professor, Department of Costume Design \& Fashion, Hindusthan College of Arts \& Science, \\ Coimbatore, India. \\ ${ }^{2}$ Assistant Professor, School of Design, Presidency University, Bangalore, India. \\ ${ }^{3}$ Pattern Making Instructor, JD Institute of Fashion Technology, Mumbai, India.
}

\begin{abstract}
Green production is a business strategy that focuses majorly on making a profit through eco-friendly operations. Sustainability is a holistic approach that improves the quality of life by making things environmentally friendly. To be Sustainable there is a need for many individual efforts from all frames of the society to reduce waste. One of the major industries that have to be sustainable is the movie-making industry that is Hollywood.

When we discuss Hollywood movies we usually focus on the sustainability of camera, film, and all such aspects. But apart from that, how to make the industry green is a major focus that has to be done on artwork and the costume. The production team mainly concentrates on' zero waste' the design and reuse of the resources. Thus no trash will be produced during the production or nothing will be sent to landfills or incinerators.
\end{abstract}

Nowadays the greatest challenge which is faced by the art director and the customer is to bring the set and costume upto the level of sustainability. Thus as teamwork, the crew of this big-screen industry is trying to bring out the huge impact of being eco-friendly in the production of Hollywood movies.

Keywords: Green Production, Recycling of costume and film set

\section{INTRODUCTION}

Environmental sustainability has occurred in other sections but that has become an issue also in the cultural sector especially the big screen industry. The need for the term sustainability in the film industry started in the early 1990's. The attention was demonstrated in the form of environmental content, environmental activism and the philanthropy of celebrities rather than the production operation.

Globally many film studios have adopted sustainability initiatives that include 'Big five', 'Universal Pictures', Walt Disney pictures',' Warner Bros',' Columbia' and like that as an initiative to achieve sustainability. The sustainable production forum was launched in 2016 that brings together the leaders of the film industry to discuss sustainable practices in production rather than simply environmental friendly content.

\subsection{Sustainable Film Production:}

Sustainable Film Production is dealing with social and environmentally responsible decision-making in the field of Preproduction and Post-production of movies.

The sustainability of film production must start along with the launch of the project and involve all the key stakeholders including the directors, film producers, production, set, costume designer, cast, crew, etc. Film production can be International about helping communities in an economic way. 
Vol. 8, Issue 10, October 2021

DOI: $10.17148 /$ IARJSET.2021.81028

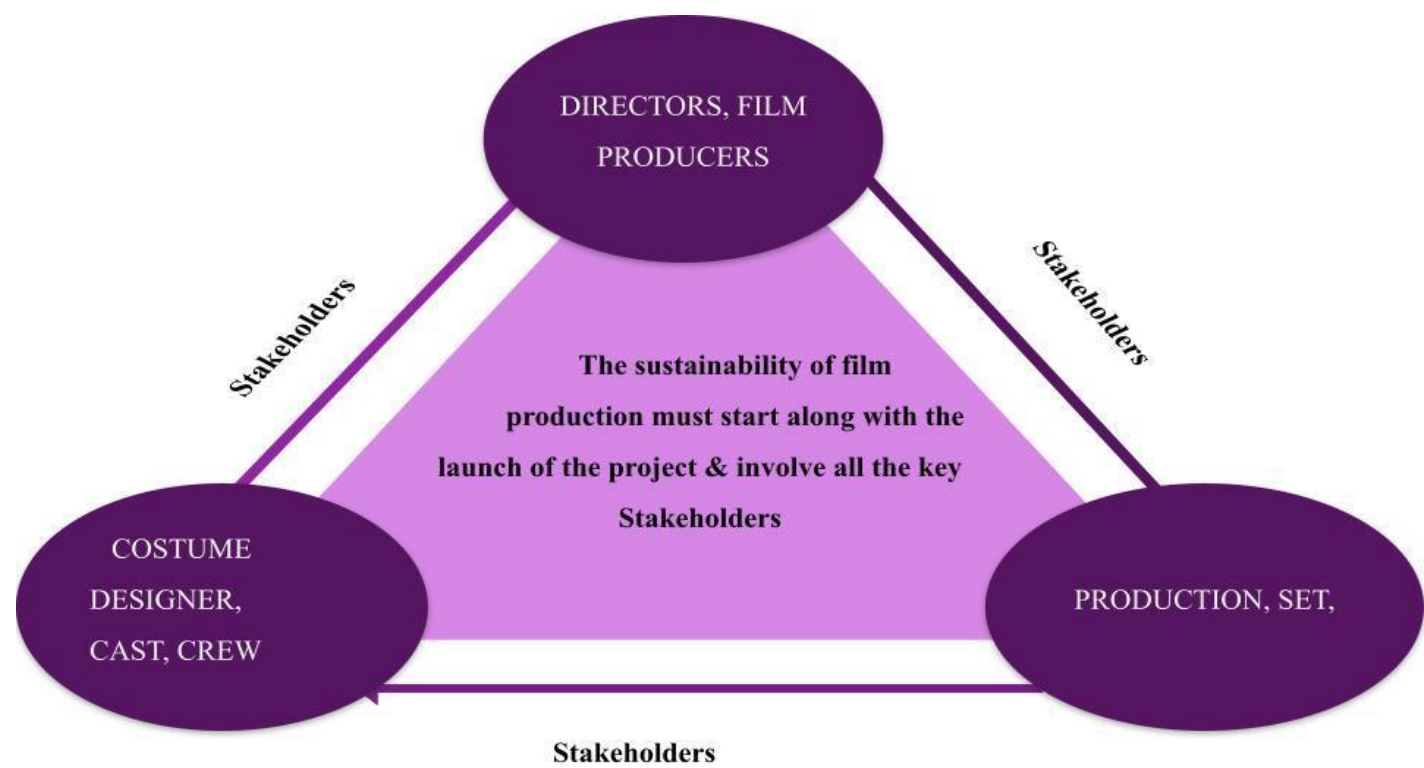

Fig.1 Sustainable Film Production

Film making is something that is very interactive towards sustainability and is friendly with the production, meaning it seems to be like a task that is difficult to deal with. The concern about the action of protecting the environment reaches the film industry to make it a more sustainable and respectful field. Ideally, everything that is related to film should have to be made sustainable and ethical. The Green Production guide has formulated a series of open source tools that includes the carbon calculator to help production implement sustainable practices effectively. To speak about the film industry it has to cover up at most all the fields related to this industry among which the most important and prioritized ones are the costume and the film sets, which we can say to be the heart of the film industry. It is a field that needs a deep discussion on the effectiveness of bringing sustainability after pre-production and post-production activities.

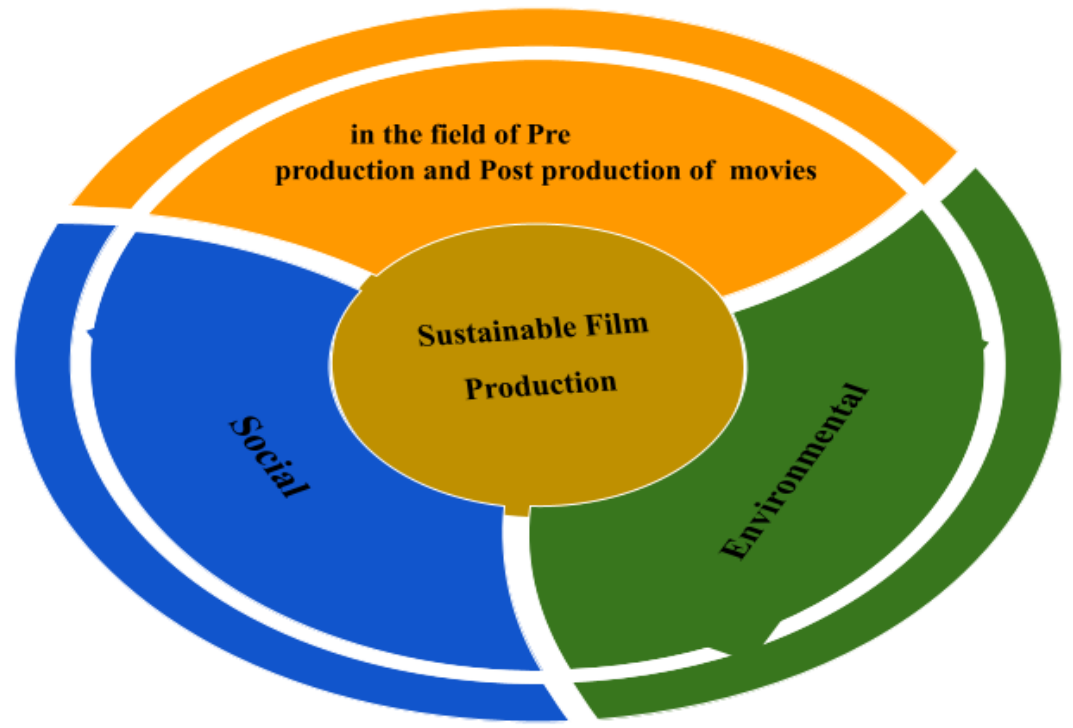

Fig.2 Sustainable Film Production

\subsection{Hollywood and fashion sustainability on set}

Usually, fashion is something that deals with the red carpet. But apart from that, there is another facet of the fashion industry that can be even more ways. According to the experts who have worked in the costume department of film projects, the amount of energy that goes into the outfit of actors on a single project can be massive. As per their view, for a single movie project, the costume designer will buy or make more clothes for a person which will be more than what he owes for a whole lifetime. It is to be said that, if Hollywood produces over 700 films every year, the movie 


\title{
International Advanced Research Journal in Science, Engineering and Technology
}

\author{
Vol. 8, Issue 10, October 2021
}

\section{DOI: $10.17148 /$ IARJSET.2021.81028}

industry will send 2.5 million garments into the fashion limbo. The production is trapped. Movies backed by large production companies usually rely on costume warehouses that hold pieces and are said to be reused. But still, there's a problem faced again in renting the costume from a warehouse which occurs if the production is not dealing with a large production company or if the production is not in Los Angeles or in New York City, it will be difficult to access these types of warehouses. Even there will be limited options which may lead to clothing from Vintage and contemporary stores. So most of the production team will collaborate with costume designers and create costumes from scratch.

The present-day scenario which happens in product sets is that the costume department usually depends on Amazon for fast fashion stores for their costume because the clothing is inexpensive and the delivery of the costume is fast. The costume department from buying in bulk also because sometimes the exact measure of the size of the character is unknown. These items are sometimes returned or something thrown away or burnt, it will never be restored. As per Union law, used clothing has to be cleaned at least weekly.As a concept of sustainability 'Energy star washing appliance and cold wash' is recommended for cleaning to reduce energy use. Some garments have to be dry cleaned rather than washed but they release harmful PCE solvents into the environment. Nowadays alternatives like PERC-free dry cleaning and wet cleaning are recommended.

As a part of green fashion, the query has been raised leading to the after use of costume once the production of a movie ends. Some of the custom pieces that the big production companies own will go to costume houses so that they can be checked then borrowed again. Some clothing ends up in that storage. There are certain organizations like Earth Angel Work that donate the remaining item to the local organization and recycle any scraps. In the absence of sustainability, standard companies like Earth Angel are working with the production team to create green assets on a case-by-case basis. Sustainable preference has to be a part of the infrastructure. As a lead to sustainability, the costume has come out with some surpassing ideas, as they have decided to purchase second-hand or recycled clothing and accessories which are appropriate. They have planned to support Canadian and BC designers with environmental credentials. They have awarded the use of garments and accessories from endangered species, as they have planned to repair and alter garments rather than buying new ones. Avoid dry-cleaning in the cleaning process. They prefer going for an energy-efficient machine and not to use solvent perchloroethylene. For standard sustainability practice, the industry needs to have more oversight and requirements on top industry professionals. And those practices have to be started from the local level with film commissions creating infrastructure to make their community greener.

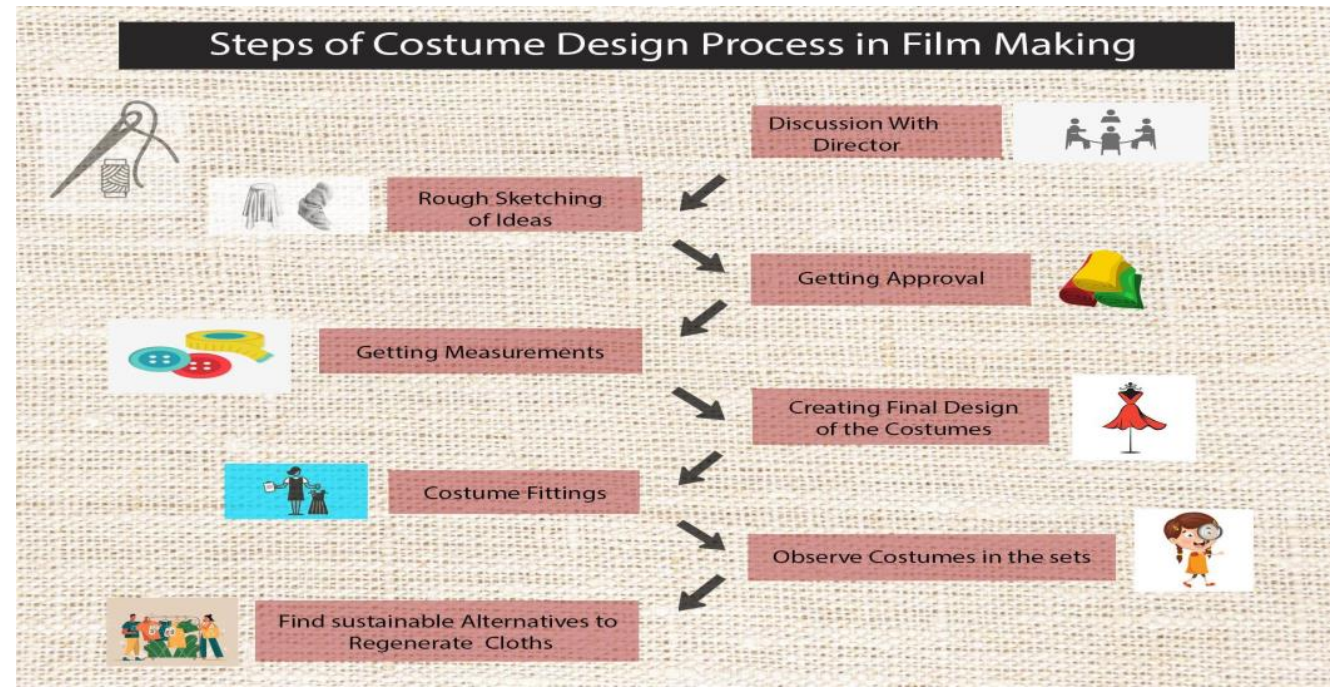

Fig.3 Hollywood and fashion sustainability on set

\subsection{Sustainable production and set design}

From script to vision, design to build, shooting to pack-up- planning is everything. When Sourcing material, building sets, and diverting waste from landfills. Most of the films come together in a relatively minimal amount of time. Additional properties and materials are brought into sets if required and various steps are taken to make sure that whatever properties are needed are included.

To quote as an example, during the production of the Hollywood action movie Fast and Furious season 7, 230 cars were wrecked. Film and TV productions that don't have big action scenes even require a lot of design for sets. but it was always a surprise there what would happen to the movie set after the film was wrapped. Most of the time tons of the material are wasted which leads to additional expenditure. In that case also, for demolishing, much of the budget dries up. So even the demolition of the set will also be left behind as a half-demolished. search half left search will also cause 


\title{
International Advanced Research Journal in Science, Engineering and Technology
}

\author{
Vol. 8, Issue 10, October 2021
}

\section{DOI: $10.17148 /$ IARJSET.2021.81028}

so many environmental issues which can't be used up or which can be put as trash as well. To show the set as an ecofriendly one it is not enough to act eco-friendly on location alone, but also certain other factors suggest logistics transport and even the workflows within the production has to be considered.

To handle this issue there are better ways of planning for a sustainable set design that has to be done before production. While discussing more eco-friendly possibilities offset design in demolishing- the movies can be shot in a studio. recycling is another method of keeping a sustainable set. The material used to create sets is typically of higher quality and more durable. As to preserve these materials and to go green with the movie sets, the material that has been used for other sets can be repurposed so that the property dismantled can be reused for the set also.

Sometimes after the production has wrapped this set has to be left as it is. For example, the said bill for the movie Harry Potter has been kept as it occurs and it was used for the production of the whole series of Harry Potter and even after the completion that has been retained and later converted as tourist spots. Another option is to sell or donate unwanted set material to the local theatres, High Schools for other production before opting for disposal. As a part of Go Green said paint and products of the environmentally friendly label and after the usage, the paint and the product have to be disposed of properly or returned to the retailers or stores for further use. If it is necessary to be used means the recycled wood or wood from a magnified forest can be used. Instead of purchasing new items, furniture, or some computer equipment, those items can be taken for rent which helps in preventing the accumulation of used-up products.

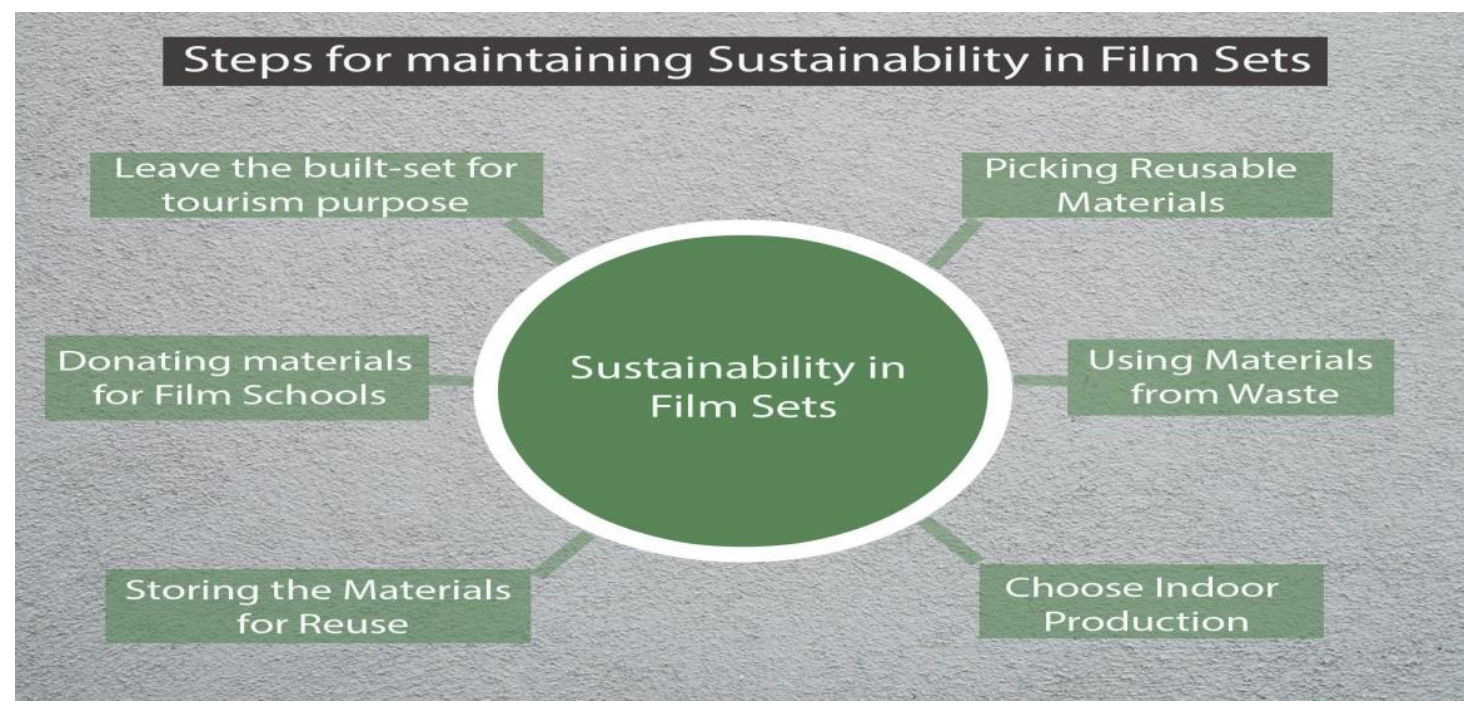

Fig.4 Sustainable production and set design

\section{CONCLUSION}

Filmmaking by its nature itself is very counteractive toward sustainability. The Sustainable Production Champion award recognizes individuals that "go above and beyond to advance sustainable production in the motion picture industry" and is given for the projects that are working with the aspect of sustainability. The Global dedication to sustainable production by the industry has cultivated in the "sustainable products forum" every year in Vancouver, for collaboration and dedication on Sustainable film production which brings together the leaders of the film industry and to discuss the sustainable practice in production rather than simply environmental friendly content does as a group effort the theme word sustainability can be achieved along with various fields of life in the field of cultural representation also.

\section{REFERENCES}

1.https://greenfilmshooting.net/blog/en/2015/04/20/sustainable-production-and-set-design/

2.https://www.creativebc.com/industry-sectors/motion-picture/reel-green/best-practices\#art-set-dec-construction

3.https://lab.cccb.org/en/eco-friendly-practices-in-the-film-industry/

4. https://www.refinery29.com/en-au/hollywood-sustainability

5.https://beverlyboy.com/filmmaking/what-happens-to-movie-sets-after-filming/

6.https://www.studiobinder.com/blog/13-ways-to-green-your-production-right-now/

7.https://en.wikipedia.org/wiki/Sustainable_film_production 